\title{
Sellos, turismo y gastronomía: El papel de la gastronomía en la promoción turística de España a través de los sellos de correos
}

\author{
Guillermo Navarro Oltra* \\ Universidad de Castilla-La Mancha (España) \\ F. Xavier Medina** \\ Universitat Oberta de Catalunya (España)
}

\begin{abstract}
Resumen: El objetivo de este artículo es analizar el papel de los sellos de correos en tanto que instrumentos de promoción turística, a través de la gastronomía como motivo representado. Para ello, analizaremos el caso de las emisiones de estas características en España, desde sus primeras representaciones, a finales de los años ochenta del siglo XX, hasta el momento actual. A través del análisis propuesto, observaremos, por un lado, el uso y la evolución de estas imágenes en su relación, tanto con aquello que representan y con sus usos y valores sociales, como con el interés como atractivo turístico que de ellas se desprende. Por otro lado, observaremos también la íntima relación que existe entre dichas imágenes gastronómicas, algunos de los distintos momentos de la historia reciente del país y su relación con las diferentes políticas institucionales llevadas a cabo.
\end{abstract}

Palabras Clave: Sellos de correo; Gastronomía; Turismo; Identidades; España.

Stamps, tourism and gastronomy: The role of gastronomy in promoting tourism in Spain through the postage stamps

Abstract: The aim of this article is to analyze the role of postage stamps as instruments for tourism promotion, with gastronomy as a representative motive for travel . To do this, we will analyze the case of the emissions of stamps with these characteristics in Spain, from the first representations, at the end of the eighties of the XX century, through to present times. Through the proposed analysis, we will observe, on the one hand, the use and evolution of these images in their relationship, both with what they represent and with their social uses and values, and their interest as a tourist attraction. We will also observe the intimate relationship between the gastronomic motifs of the stamps and various different moments in the recent history of Spain and their correlation with institutional policies.

Keywords: Postal stamps; Gastronomy; Tourism; Identities; Spain.

\section{Introducción}

Turismo y gastronomía se encuentran hoy, y cada vez más, indisolublemente asociados a los ojos tanto de instituciones y de promotores turísticos como de visitantes. Parece haber, en este sentido, un cierto consenso en relación con el papel de la gastronomía como un elemento de cultura y de identidad y, desde ahí, su conversión en un elemento patrimonial. Una vez hecho este recorrido, no es extraño dar el paso siguiente, que es observarla como un atractivo turístico que es capaz de despertar el interés de propios y extraños, pero en cualquier caso, de visitantes.

\footnotetext{
Director del Departamento de Sistemas alimentarios, Cultura y Sociedad, Universidad de Castilla-La Mancha. Cuenca. Guillermo; E-mail: Navarro@uclm.es

* Departamento de Arte, Universitat Oberta de Catalunya (UOC). Barcelona; E-mail: fxmedina@gmail.com
} 
Sin embargo, dicha asociación entre alimentación-gastronomía y cultura-patrimonio (y ya no digamos turismo) es relativamente nueva. Un hecho tan cotidiano como la cultura alimentaria que, solo recientemente, ha pasado a ser digno de ser considerado como un aspecto relevante de la cultura y, por ende, de "patrimonialización". Conforme el prisma del patrimonio (entendido como construcción social) se han ido ampliando aspectos de la cultura inmaterial antes difícilmente aprehensibles, se han incorporado a las listas de lo "patrimonializable" y, aspectos tan cotidianos como aquellos que se refieren a la alimentación, que forman parte intrínseca del día a día, de lo popular, pero no de la Cultura con mayúsculas (además de la subalternidad a la que se han encontrado abocados, por encontrarse, al menos en su parte más privada, ligada al ámbito de lo femenino), se han convertido en dignos de formar parte de esta última y, por lo tanto, de oficializar su pertenencia y su importancia en relación con nuestras identidades (Medina, 2017: 106).

Desde esta perspectiva, la alimentación se ha sumado (a partir de finales de la década de los años ochenta del siglo pasado, en el caso de España) al resto de atractivos turísticos seleccionados como dignos de ser destacados en la promoción turística institucional (es decir, aquella llevada a cabo desde el ámbito público).

En este sentido, y a un nivel institucional amplio, uno de los instrumentos de los que el Estado dispone como herramienta tanto de representación de la cultura, de la "identidad nacional" y del patrimonio como, también, de promoción turística son los sellos de correos, los cuales, además de ser un instrumento de franqueo oficial, transmiten con sus diseños mensajes originados por el Estado con la intención de influir en sus usuarios y, por otro lado, su atractivo y variedad los hace susceptibles de ser coleccionados. Por otro lado, se convierten, a través de sus representaciones, en pequeñas ventanas abiertas al mundo (internacionalmente) que transmiten imágenes de aspectos relevantes y atractivos de un determinado país.

Ahora bien, habría que señalar que el sello postal ya no puede ser considerado el objeto de uso cotidiano que fue hace una generación -pese a que se siga utilizando en muchos países en cifras de millones de ejemplares- y que su presencia en nuestra vida diaria ha sido relegada a un segundo plano con el advenimiento de las comunicaciones electrónicas. (Navarro Oltra, 2015b: 16). Aunque si bien es cierto que los sellos postales siguen diseñándose para atraer al coleccionista, gran parte de las intenciones comunicacionales siguen siendo las mismas que señalaba Carlos Stoetzer a mediados del s. XX y más aún en lo referente a la promoción turística, puesto que las imágenes que muestran los sellos, tanto dentro como dentro como fuera de las fronteras del país emisor, intentan atraer a posibles visitantes mostrándoles lugares donde pueden pasar sus próximas vacaciones, en el caso de que se lo puedan permitir. En un principio, estas imágenes -normalmente de los lugares y monumentos más importantes- aparte de fomentar el orgullo nacional son símbolos por los cuales el país es conocido en todo el mundo, por lo que intentan fomentar una actitud favorable hacía el país emisor (1953: 3-4).

Sin embargo, es importante tener en cuenta que el objetivo perseguido por cualquier Estado al emitir propaganda -en cualquier medio- es que esta funcione y ello depende de cómo sea percibida y cuál sea el efecto que produzca en el receptor. Por lo tanto, cuantas más veces el individuo que responde al estímulo vea el mismo sello postal -suponiendo que este esté correctamente diseñado- mayor será la probabilidad de que, con el tiempo, desarrolle la respuesta o actitud deseada por el emisor (Strauss, 1975: 158). Pero esto es algo sobre lo que no puede profundizar debido a que los estudios sobre el impacto de los mensajes emitidos en los sellos postales y su impacto sobre la población son inexistentes, incluso en la época del donde el consumo y utilización del sello postal estaban en su apogeo.

Aun así, se considera importante aclarar este punto y recalcar la importancia que tiene el sello postal como herramienta promocional y portadora de los mensajes ideológicos de un Estado sobre cualquier tema, pero más aún en el caso del fomento del turismo y la gastronomía a través de este documento de valor.

El objetivo de este artículo es, pues, el de analizar el papel de los sellos de correos en tanto que instrumentos de promoción turística, a través de la gastronomía como motivo representado. Para ello, analizaremos el caso de las emisiones de estas características en España, desde sus primeras representaciones, a finales de los años ochenta del siglo XX, hasta el momento actual. A través del análisis propuesto, observaremos, por un lado, el uso y la evolución de estas imágenes en su relación, tanto con aquello que representan y con sus usos y valores sociales, como con el interés como atractivo turístico que de ellas se desprende. Por otro lado, observaremos también la íntima relación que existe entre dichas imágenes gastronómicas, algunos de los distintos momentos de la historia reciente del país y su correlación con las diferentes políticas institucionales llevadas a cabo.

\section{Preliminares: el sello postal y sus funciones}

Con anterioridad a 1840, fecha en que se emitió el primer sello de correo, el importe de las tarifas establecidas para el envío de cartas era pagado por el destinatario, quien no siempre abonaba el importe 
del servicio, evitando así su entrega. Con la Revolución Industrial en pleno apogeo, la cantidad de envíos por correo crecía incesantemente, y el sello prepagado surgió como la manera más sencilla de que el Estado se asegurara que los portes del envío quedaban cubiertos (Altman, 1991: 5). En los siguientes 20 años casi toda Europa y sus dependencias, así como partes de América, contaban con servicios postales estatales (Altman, 1991: 6) y desde entonces hasta hoy, a diferencia de otros medios en el campo de la comunicación visual, éstos han permanecido como monopolio gubernamental incluso en los países democráticos (Frewer, 2002: 6).

Debido a su origen -es emitido por un monopolio controlado por un poder político (Bonacina, 1998: 17) - el sello de correo está bastante lejos de ser considerado ideológicamente inocente o políticamente neutral. Más bien al contrario, es apreciado como un lugar donde se resuelven conflictos sociales y políticos y se afianzan normas sociales y de conducta (Dobson, 2002: 23); esto es, al sello se le supone "agencia social" (Gell, 1998: 19). Ésta puede constatarse por las siguientes características:

a) sirve como certificado de una relación contractual entre su comprador y el Estado;

b) con sus diseños, transmite mensajes originados por el Estado con la intención de influir en sus usuarios; y

c) su existencia crea el deseo en la gente de coleccionarlos (Frewer, 2002: 3).

Desde un punto de vista semiótico, el sello de correo posee una doble función, la indicativa y la representativa:

"The primary function of the stamp is to indicate the name of the country of the mail to which it is attached and the postage paid. (...) The representative function is an extension of the definitive function in that it proposes a representative image of the country of issue in a way that is more visible and evocative than mere provision of the country's name. It usually takes the form of some identifying icon, a monarch's head, coat of arms, or a geographical or architectural feature" (Scott, 1995: 6).

El sello postal ha cumplido, desde su inicio, las mismas funciones indicativa y representativa que las monedas, incluso fuera de las fronteras estatales, puesto que su utilidad principal -permitir el envío de correo- también continúa en otros países. Ésta es una de las razones que lo ha llevado a ser considerado como una "ventana" al interior del Estado emisor que ilustra cómo éste desea ser visto por sus propios ciudadanos y los que habitan más allá de sus fronteras (Brunn, 2001: 315), y este hecho resulta de una especial relevancia en relación con el turismo, tal y como tendremos ocasión de ver más adelante.

La inclusión de imágenes en su diseño hace suponer que el sello de correo desempeña otra función aparte de certificar que se han pagado los costes del envío, puesto que, de otra manera, con un simple indicativo bastaría. Ahora bien, aunque las imágenes mostradas en un sello sean superfluas a la hora de indicar que se ha abonado su importe, esto no implica que no se les haya asignado una función de manera premeditada. Estas imágenes suelen representar símbolos nacionales, dentro de un amplio espectro de temas que abarca desde banderas y mapas a flora y fauna, pasando por artistas, monumentos, acontecimientos históricos presentes o pasados (Brunn, 2001: 318) o imágenes gastronómicas, como es el caso del análisis propuesto en este capítulo. Muchos de los símbolos utilizados, además de proporcionar un sentimiento de identidad y de pertenencia, son un apoyo a las estructuras administrativas y legales -fronteras, nombre, constitución, alianzas- que constituyen la razón de ser de un Estado (Brunn, 2001: 315). Sin embargo, estos símbolos no son estables ya que, con el devenir de los tiempos, los gobiernos, las políticas y las intenciones cambian.

“(...) a nation's self-image and identity are a mutable, discursive construct, 'a system of cultural representation' made up of 'symbols and representations' informed by various dominant narratives such as those generated by the state and national institutions" (Jones, 2004: 165).

Estos cambios, que se reflejan en las imágenes plasmadas en los sellos, muestran al observador (coleccionista o no) quién es homenajeado y quién no lo es, qué paisajes, elementos o ciudades son mostrados y qué es celebrado, así como qué mensajes sutil o abiertamente incitan al nacionalismo o a cualquier ideología específica (Brunn, 2001: 317), todo lo cual forma parte de la propaganda propuesta por el Estado emisor, ya que un Estado decide, a través el gobierno que lo rige, qué imágenes y textos deben aparecer estampados en los sellos, ya sean estos definitivos o conmemorativos. Hay que señalar, no obstante, no siempre se transmite propaganda a través de los sellos. 
En los sellos corrientes o definitivos - que son aquellos de tirada ilimitada y de uso prolongado- la intención emisora de mensajes por parte del Estado es menos evidente, puesto que, principalmente, estos sellos se utilizan como certificado de pago y además de indicador del país de procedencia. Estos sellos suelen contener la efigie del jefe del Estado, algún símbolo heráldico o simplemente una cifra, aunque esta opción es la menos utilizada. El uso de cualquiera de estas imágenes como indicativo de un país, reforzada con la inclusión del nombre de éste, es una decisión sancionada por el Estado. Por lo tanto, está cargada de intencionalidad política. Por su parte, en los sellos conmemorativos -que, como su nombre indica, conmemoran un acontecimiento, son de tirada limitada y están destinados, principalmente, al coleccionismo- la intencionalidad gubernamental en la elección de las imágenes a incluir es más clara. El Estado elige qué acontecimientos celebrar, y estos pueden ser importantes fechas históricas, nacimientos de personajes célebres o aniversarios de sus creaciones... O elementos destacables de la gastronomía, entre otros muchos motivos. Pero estas selecciones de temas no son, de ningún modo, gratuitas; a través de los temas o personajes celebrados podemos deducir el cariz ideológico del Estado que los ha emitido, puesto que:

"los sellos postales sólo muestran imágenes favorables del Estado emisor, especialmente cuando se representa la historia, pues no hay menciones a genocidios, atrocidades o derrotas. Otro tanto ocurre con la representación de la industria o el turismo, actividades éstas de las que sólo se muestra la cara amable obviando, por ejemplo, la contaminación o diversos tipos de turismos éticamente reprobables cuando no directamente ilegales. (...) Y esto ocurre en cualquier país que cuente con una producción postal propia, y España no es ni fue una excepción" (Navarro Oltra, 2015a: 14-15).

\section{Preliminares (2): El turismo como instrumento ideológico y de desarrollo}

Casi paralelamente al desarrollo de los sellos de correo, aún en el siglo XIX, comienza a manifestarse la visión y la organización del turismo por parte del Estado en tanto que un sector estratégico. En el caso de España, encontramos la presencia de viajeros (viaje cultural, frecuentemente con un marcado carácter orientalista) o de un incipiente turismo balneario, pero no unas estructuras de promoción turística establecidas como tales (Storm, 2013). Es en estas estas décadas cuando el Estado comience a ocuparse del turismo, adelantándose así buena parte de países europeos. Según Pack, el escaso número de visitantes extranjeros en España en comparación con otros destinos como Francia, Italia o Suiza, motivó que el gobierno decidiera fomentar el turismo en tanto que sector económico a tener en cuenta, al mismo tiempo que para corregir las ideas sobre España que la presentaban como un país primitivo e inhóspito (Pack, 2006: 49 y ss.).

Será en 1905 cuando se inicie la organización administrativa del turismo en España (Pelejero, 2004: 268). A partir de ese momento, este mismo autor señala paras el desarrollo del turismo en España a lo largo del siglo XX, tres grandes momentos: el primero (1900-1936), marcado por la intervención del Estado, es decir, el periodo en que tiene lugar la emergencia del turismo moderno en España; el segundo, durante los años de la dictadura franquista (1936-1975), cuando el turismo dejó de ser minoritario y se transformó en un fenómeno de masas; y tercero, en el último cuarto del siglo XX, con consolidación de España como destino turístico de primer orden y la asunción de competencias de turismo por parte de las comunidades autónomas (ibíd.).

\section{Turismo y gastronomía: un binomio en construcción}

No es nuestro cometido en este artículo el analizar la evolución del turismo o de la gastronomía en España a lo largo del siglo XX. ${ }^{1}$ Sí que nos interesa señalar, sin embargo, algunos aspectos que marcan su evolución. Por un lado, el creciente aumento de turistas que visitan el país, y que acompaña a nivel internacional al desarrollo industrial que tiene lugar especialmente en Europa tras la segunda Guerra Mundial, con una nueva concepción tanto del trabajo como del ocio; por otro lado, la cada vez mayor institucionalización y organización turística en España, especialmente a partir de los años cincuenta; en tercer lugar, la evolución de la concepción oficial del turismo, ligada a más a la propaganda del Estado en un primer momento, y convirtiéndose cada vez más como un importante activo económico con el paso del tiempo; y, no en último lugar, la creciente importancia que se otorga al turismo en relación 
con la creación de una imagen exterior de España que, especialmente a partir de la década de los cincuenta, puede contribuir a acabar con el aislacionismo del país, a abrirse a Europa y a otros países (especialmente a los Estados Unidos) y a dar una cierta imagen de modernidad de cara al exterior. En todo este panorama, vemos cómo la gastronomía irá ganando poco a poco terreno en España a todo lo largo del todo el siglo XX, aunque partiendo desde posiciones relativamente difíciles, ya que, si bien hoy es observada casi sin discusión como un atractivo turístico de primer orden, su nexo con el turismo no siempre ha estado tan claro. Y es que, ya finales del siglo XIX y las primeras décadas del XX, la relación de los viajeros con las cocinas populares era, cuando menos, difícil. Por otro lado, las élites que veraneaban en localidades balnearias como San Sebastián tenían la cocina francesa como referencia, elaborada a menudo con productos locales, pero con un gusto intencionadamente alejado de lo local. Como señala González Turmo (2007: 198): "el turismo selecto reinventó la gastronomía, la arquitectura y el paisaje, evitando lo autóctono, aunque persiguiendo un efecto pseudo natural”.

El turismo empieza, sin embargo, a institucionalizarse. Como señala Eric Storm, los funcionarios no tardaron en tomar las primeras medidas para profesionalizar el sector turístico ${ }^{2}$ y ya en agosto de 1939 aconsejaron adaptar la comida de los hoteles a los gustos internacionales, evitando guisos regionales con características demasiado raras o condimentos excesivamente fuertes y desconocidos fuera de España, aunque sin dejar de servir platos españoles como la paella, el cocido a la madrileña o la tortilla a la española. Hacia finales de los años cuarenta y principios de los cincuenta, el deseo de salir del aislamiento internacional y las necesidades económicas -sobre todo la falta de divisas- fueron un estímulo para los que veían el turismo internacional desde un enfoque pragmático (Storm, 2013; Pack, 2006).

El fenómeno turístico no empieza, sin embargo, a desarrollarse hasta bien entrados los años cincuenta. De finales de esa década (1957) son las primeras regulaciones de cafeterías y hoteles. En 1965, estando Manuel Fraga al frente del ministerio competente, se crea el estatuto ordenador de las actividades turísticas privadas, con la regulación de "hábitos que hoy en día parecen elementales, como la existencia de lista de precios, libro de reclamaciones, menús del día, traducción de las cartas a otros idiomas y la limpieza en baños y cocinas" (González Turmo, 2007: 201). Será entre 1964 y 1965 cuando se cree y se regule el que a partir de ese momento sería conocido como menú turístico. Cualquier local que sirviera comidas y bebidas tenía la obligación de ofrecer, bien visible, un menú pautado con unos primeros compuestos por entremeses o sopa, pescado, carne o huevos como segundo y fruta, dulces o queso de postre; además, pan, un cuarto de litro de vino o bien otra bebida (sangría, cerveza, refresco...). Los platos que componían el menú debían de ser lo más típicos posible de la cocina española conocida internacionalmente, y especialmente la paella, el cocido o la tortilla española.

Un caso particularmente interesante sobre la promoción turística a nivel nacional de determinados platos es el de la construcción de la paella (el primero de los platos representados en un sello de correos en España) en tanto que emblema gastronómico español por antonomasia. En este sentido, tenemos que el desarrollo turístico y las políticas que en su momento lo fomentaron construyen la paella como monumento nacional durante los años centrales de la dictadura franquista, convirtiéndola en una manifestación gastronómica de la representación de la nación española que, en cierto sentido, ha llegado hasta hoy en día.

Como señalan Duhart y Medina (2009: 337-338), para los extranjeros, la paella es hoy en día un monumento típicamente español (más que valenciano) que es necesario visitar con tenedor. Mientras que dentro de España (y especialmente más allá de la comunidad valenciana, pero no solo) puede a veces considerarse como una herencia que pesa, un plato-tópico que a menudo es mejor vender que consumir. Las operaciones de propaganda y publicidad emprendidas por el Ministerio de Información y Turismo español (1952-1977) siguen dando resultado en el campo de lo culinario.

En efecto, la paella y las otras especialidades que se elevaron a la categoría de emblemas un tanto artificiales (muy precozmente sostenidos por los deseos que despertaron en los veraneantes) conservan un verdadero poder de atracción. El menú turístico sobrevivió a la llegada de la democracia y actualmente continúa muy en vigor.

Diferentes autores han situado la paella como el plato emblemático de la "cocina española" (cf. Fribourg, 1996: 354; Hubert, 2000). La identidad española, en referencia a la paella, uniformiza el territorio y hace partícipes del plato a todas las comunidades autónomas (lo consideren éstas o no dentro de su patrimonio culinario particular).

Dondequiera que se encuentren en España, los visitantes extranjeros siguen buscando la paella. El auge turístico español construye y aprovecha especialmente una paella unificada, que el turismo mismo contribuyó a establecer, y que se caracteriza por una guarnición mixta, barata y definitivamente muy estandarizada. Estas dos últimas características hacen de ella una verdadera innovación. Aún hoy, 
los gastrónomos denuncian a menudo este plato donde elementos como las gambas, las almejas o los mejillones se combinan con el pollo o el conejo, como una herejía, y donde el rojo de los crustáceos se une al amarillo del arroz (cada vez más fruto del colorante alimentario y menos del azafrán) emulando los colores de la bandera española.

A pesar de ello, la elaboración de esta paella mixta se extendió fuera de los restaurantes para turistas. Casi toda España se ve afectada y no se libra de este movimiento: la paella unificada se ha convertido, en parte gracias al turismo, en la paella estándar, la más popular también. El plato creado en los restaurantes para turistas, pilar de un "falso-contacto" a precio accesible con el arte culinario español, ha penetrado en la intimidad del hogar y las celebraciones familiares.

Sobre el conjunto del territorio español, la paella ocupa hoy un lugar destacado entre los platos elegidos por las asociaciones y los grupos más diversos cuando se trata de comer juntos. Su coste de preparación es muy flexible y su perfecta adaptación a un servicio rápido, sin modales y generoso, explica mucho tal éxito, que es suficiente para hacer de ella un plato nacional. El estatuto de emblema culinario nacional conferido a la paella, sin dejar de ser artificial, se volvió con el tiempo muy real, por el simple juego de la fuerza de las representaciones. No es pues de extrañar que la paella fuese el primer plato elegido para ser representado en un sello de correos, en tanto que emblema de la gastronomía patria y, al mismo tiempo, en tanto que proyección hacia el exterior de los atractivos turístico-gastronómicos españoles.

Como señalan Bueno y Ortega (1998: 14), los años sesenta y setenta conllevan "la aparición de una cocina (...) que reunía lo peor de nuestras tradiciones culinarias, popularizó entre nuestros visitantes foráneos una versión entre folclórica y degradada de platos como la paella, el gazpacho, el cocido, la sangría y demás. El resultado fue una cocina barata -que muchos restauradores cobraban cara-, hecha sin cuidado y de espaldas a las auténticas cocinas regionales, a las que se prestó el peor servicio que jamás les había rendido una generación de cocineros". Resulta especialmente interesante en este punto observar que esta cocina de grandes representaciones, de platos emblemáticos y de etiquetas simplificadoras será, precisamente, aquella que tendrá una mejor cabida en los sellos de correos, los cuales buscan precisamente imágenes simples, homogeneizadoras, fácilmente reconocibles, y que se correspondan con los símbolos y niveles de identidad nacional española propuestos y explotados desde las instituciones oficiales estatales.

La llegada de la democracia marcará distintos caminos que han llevado hasta el momento actual. Un cambio importante fue la decisión de traspasar las competencias turísticas a las comunidades autónomas a partir de 1979. Las cocinas regionales o de los distintos territorios se refuerzan, se reactualizan e incluso se reinventan (capitaneadas por la cocina vasca y, a no mucho tardar, la catalana). Y llega también, desde el País Vasco (Arzak, Subijana...), la llamada nueva cocina, que busca la innovación, la "sorpresa" y el buen producto, actualizando las cocinas tradicionales y aportando la visión creativa del cocinero que, cada vez más, investiga. El catalán Ferran Adrià supondrá el punto álgido de un momento culinario que, sin duda alguna, transformará la(s) cocina(s), no solo española(s), sino a nivel general, situando en la primera línea internacional de reconocimiento la imagen de una cocina española que, como señalaba González Turmo (2007: 209) “(...) no partía en buena posición (ya que) había tenido durante siglos mala prensa fuera de las fronteras estatales. En las últimas décadas, los profesionales del sector, amén de divulgadores, administración y legisladores, han hecho un importante esfuerzo por vencer esa inercia y dar a conocer las diversas y renovadas cocinas del Estado. No cabe duda de que lo han conseguido".

\section{Turismo y gastronomía en el sello postal}

\section{El turismo en el sello postal}

Todo este panorama expuesto, nos muestra distintos intereses y momentos de coincidencia y de intersección en los cuales la promoción y la gestión turística y la proyección de imagen (interior y exterior) que proporcionan los sellos de correo, encuentran diferentes lugares comunes que nos resultan del máximo interés.

Pese a la aparición de espacios monumentales y paisajísticos de marcado interés turístico en los sellos postales desde principios del siglo XX, no será hasta la década de los años sesenta cuando, paralelamente a las políticas públicas estatales en relación con la promoción turística de España tanto en el interior como en el exterior, se establezca la emisión de varias series filatélicas cuya temática es específicamente el turismo. Estas emisiones no hicieron sino concretar en determinadas series una tendencia que se inició a en el primer tercio del siglo XX y que, independientemente del régimen político, siguió aumentando hasta convertirse, en su conjunto, en el grueso de las emisiones filatélicas de España. 
Durante el reinado de Alfonso XIII, las emisiones conmemorativas que celebraron tanto la Exposición Internacional de Barcelona como la Iberoamericana en Sevilla entre los años 1929 y 1930, fueron el punto de partida de las series filatélicas que mostraban monumentos que, aparte de constituir auténticos lieux de mémoire, comenzaron a atraer la atención de posibles visitantes. Durante la Segunda República española (1931-1936/39), se emitieron algunas series que representaban diversas ciudades y eventos a través de la exhibición, no solo de monumentos concretos, sino, además, de vistas panorámicas de distintas ciudades. En el bando nacional se emitieron numerosas vistas de edificios representativos de las ciudades que se adhirieron a la sublevación desde un primer momento, y alguna que otra con un importante valor simbólico como podría ser Toledo y su Alcázar.

Una vez finalizada la contienda y con Franco asentado en la Jefatura del Estado, las emisiones filatélicas se normalizaron a través del Plan Iconográfico Nacional de (Boletín Oficial del Estado, 1944: 5303-5304), es decir, se establecieron las categorías temáticas que debían tratarse en el sello postal a partir de entonces, puesto que se consideraba un "Símbolo de soberanía, portador de valores espirituales e históricos. En cuanto viene a ser una expresión de la entidad autónoma Nacional, el sello perpetúa, pasada su momentánea función de franqueo, esa significación a los ojos de la posteridad por obra y efecto del coleccionismo" (íbid.: 5304).

Entre las categorías que se establecieron en el Plan Iconográfico Nacional son varias las que podemos considerar ligadas, de un modo u otro, al turismo y son: "Iconografía de las creaciones españolas", "Monumentos españoles" y "Paisajes españoles". Esta categorización no significa que no se hubieran emitidos sellos con estas temáticas con anterioridad a 1944, sino que, a partir de dicha fecha, y salvo en casos muy concretos, toda emisión filatélica debía ceñirse a dicha taxonomía temática.

Aparte de diversas series de sellos postales conmemorativas de algún centenario, año jubilar, etc., en las que sirvió de motivo ilustrativo, la representación filatélica de creaciones, monumentos y paisajes españoles no sería sistemática hasta 1958, año en el que se inician, con la que celebra a Goya, las emisiones de series dedicadas a pintores y sus obras, que se prolongarán hasta 1979, si bien es cierto que los artistas y sus creaciones han seguido siendo tema en los sellos, aunque no con series dedicadas con regularidad.

En 1959 comenzó a celebrarse filatélicamente con su propia serie otro motivo relacionado con el turismo, en este caso arquitectónico (y religioso): los monasterios españoles. El Estado consideró, en ese momento, pertinente emitir sellos postales con dicha temática con el objetivo "de facilitar el conocimiento de los monumentos históricos españoles, entre ellos, aquellos monasterios que por sus características merezcan tal divulgación" (Boletín Oficial del Estado, 1959: 14580).

El primero de enero de 1964, un día después de la promulgación de la ley de "Centros y Zonas de Interés Turístico Nacional" (Boletín Oficial del Estado, 1963: 18226-18230), se emite la primera serie filatélica denominada 'Turismo' puesto que, según la literatura oficial, "El sello de Correos, eficaz mensaje al mundo de nuestros valores, se presenta como el más adecuado medio de difusión de nuestra riqueza turística" (Boletín Oficial del Estado, 1964: 9) y en esta serie, concretamente, debían reproducirse "monumentos, paisajes y otros valores artísticos de nuestra nación" (íbid.). En estas series, emitidas en varias entregas a lo largo de cada año, se mostraban diversos monumentos y paisajes representativos de lugares y ciudades con un alto potencial turístico (Fig. 1). Estas series, también conocidas como "Paisajes y Monumentos", serían emitidas ininterrumpidamente hasta 1979, y con alguna nueva emisión a lo largo de la década de los años 80. A estas dos series de temática monumental y paisajística habría que sumarle la de "Castillos", emitida a partir de 1965 hasta 1972 y que, como las anteriores, se retomará en la primera década del siglo XXI.

Pero la promoción turística de un país, en este caso España, desde la filatelia, no solo se realiza a través de emisiones conmemorativas de paisaje y monumentos, sino, también, de las tradiciones, el folclore, la artesanía, la flora y la fauna. Así pues, entre 1967 y 1971 se emitieron las series correspondientes a los "Trajes típicos españoles", que junto a las series emitidas durante algunos años con la flora y fauna como temática, contribuyeron a ampliar el espectro de reclamos turísticos tanto dentro España durante el franquismo como en el exterior.

En el último cuarto del siglo XX, la lista de los temas relacionados con la promoción turística de España en los sellos fue ampliándose en series como "Grandes fiestas populares españolas", "Bienes naturales y Culturales Patrimonio de la Humanidad", "Artesanía Española", "Patrimonio Artístico Nacional", etc., así como series dedicadas a los grandes eventos deportivos y culturales, tales como el Campeonato Mundial de Fútbol de 1982, los Juegos Olímpicos de Barcelona, la Exposición Universal de Sevilla o la conmemoración del Quinto Centenario del Descubrimiento de América, todos ellos celebrados en 1992. 


\section{La gastronomía se une al turismo en el sello postal en España}

La aparición de la gastronomía como rasgo vinculado de manera inequívoca al turismo en los sellos españoles, tuvo lugar por vez primera en 1988, con la serie Turismo de ese mismo año. Esta serie pasó de mostrar monumentos y paisajes a incluir en el repertorio de temas a tratar la Arquitectura popular, los Parques Nacionales, los Instrumentos de música popular y, finalmente, la Gastronomía. Esta última, como casi no podía ser de otro modo, se mostró a ojos del mundo con uno de los platos más internacionalmente conocidos de la cocina española: la paella (Fig. 2). Esta nueva serie dedicada al turismo "acentúa sobre todo la Marca España en el arte, la gastronomía, costumbres y tradiciones que pueden atraer personas de todo el mundo, ayudando así a difundir lo mejor del país” (Correos, 2016a:14).

Hasta entonces, la gastronomía estuvo presente en algún que otro valor de las series Exporta, representada por productos como las frutas o los vinos, aunque estas series tuvieron muy corto recorrido (a diferencia, por ejemplo, de las lanzadas por otros países, como pueden ser sus homónimas mexicanas). Los vinos tuvieron entre 2002 y 2004 sus propias series filatélicas, denominadas Vinos con denominación de origen.

La gastronomía, a través del jamón de cerdo ibérico, es conmemorada filatélicamente por primera vez en 2005, en la serie Europa (Fig. 3), como pasó a denominarse en 1993 la serie emitida en España conocida como Europa-CEPT. Es esta una serie que, desde 1960, los países miembros de la Confederación Europea Postal y de Telecomunicaciones (CEPT) han venido emitiendo, en la que se mostraban e intentaba resaltar, a través de un mismo motivo ilustrativo (con algunas excepciones puntuales), el progreso y la modernidad, y se ensalzaban los frutos beneficiosos de la cooperación por medio de imágenes alegóricas. El uso de palomas, árboles frondosos o que dan fruto, flores, cadenas sin fin, líneas entrelazadas que forman tejidos o indican movimientos sinérgicos, llaves, construcciones, ruedas dentadas o barcos navegando a toda vela atestiguan el interés tomado por la CEPT en crear imágenes que representaran los fines anteriormente mencionados. A partir de 1974 se suprimió el motivo común y se optó por la fórmula del tema común, y esta serie pasó a convertirse en otro modo de promocionar la cultura, no solo europea, sino la del país que emitía cada $\operatorname{serie}^{3} \mathrm{y}$, por añadidura, el turismo, que tuvo su emisión dedicada en 2012.

Cuando la gastronomía reapareció de la mano de la serie Turismo lo hizo, ya bien entrado el siglo XXI, ${ }^{4}$ con la serie emitida en 2014 (Fig. 4) en la que la naranja comparte protagonismo en una composición con otros elementos que, según la literatura promocional "compendia lo que España ofrece a sus visitantes" (Correos, 2014a: 10). Una composición similar a la de los dos timbres que constituyen la serie Turismo del año siguiente, en la que el papel de la representación de la gastronomía española recae en la fabada ${ }^{5}$ en un sello y, en otro, en el chocolate con churros como elemento representativo de Madrid, ciudad donde se celebró la Cumbre Mundial del World Travel \& Tourism Council en abril de 2015 (Correos, 2015a: 14).

Fue a partir de ese mismo año cuando la gastronomía comienza a contar con emisiones filatélicas dedicadas en exclusiva, y otras en las que los platos típicos de distintos territorios tienen un papel preponderante en la ilustración del sello postal.

En enero de 2014 se puso en circulación, con un poco de retraso, el sello que conmemoraba a Burgos como la Capital Española de la Gastronomía 2013 y que mostraba "Un bodegón con bocados típicos -pincho de morcilla; la olla podrida ${ }^{6}$; quesos variados y una copa de vino-" (Correos, 2014a: 11). Pocos meses después, en abril, se emitió la serie Gastronomía Española, compuesta por dos hojas bloques en las que, por primera vez, se incorporaba en el engomado de los sellos una ligera sensación del aroma y el sabor de los alimentos (Correos, 2014b: 10). Una de estas hojas bloque, la dedicada a los Productos de innovación y tradicionales, "presenta un contraste entre un tradicional plato de jamón ibérico y una innovadora flor de mandarino, utilizada en la elaboración de determinados platos" (íbid.). La otra hoja bloque (Fig. 5) emitida en esta misma serie, la dedicada a la Cocina tradicional y de innovación,

"se ilustra con una frase y una imagen de Ferran Adrià, considerado el mejor cocinero del mundo, y dos platos de ajoblanco ${ }^{7}$, uno de elaboración tradicional y otro realizado por este prestigioso restaurador" (íbid.).

Ya en 2015 se emite la serie Gastronomía Española, compuesta por una hoja bloque con dos sellos, cado uno de ellos dedicado a la Capital Española de la Gastronomía de 2014 (Vitoria-Gasteiz) y 2015 (Cáceres), en los que "se presentan, respectivamente, una barra de pinchos variados característicos de Vitoria (...) y un bodegón de productos típicos de Cáceres” (Correos, 2015a: 18): principalmente jamón y embutidos. 
La gastronomía también quedó homenajeada en los sellos postales españoles de 2015, en dos series, que conmemoran dos asuntos, a priori, distintos. La primera de ellas, emitida en el mes de julio, estaba dedicada al Patrimonio Inmaterial de la Humanidad y estaba compuesta por dos sellos, uno representando a El Silbo Gomero y el otro a La Dieta Mediterránea, ${ }^{8}$ en el que el elemento destacado es una gota de aceite de oliva. La segunda emisión que comentamos es la dedicada a las Denominaciones de Origen Protegidas, en este caso, de Galicia; una hoja bloque que contiene dos sellos que presentan al Pemento de Herbón /Pimiento del Padrón y al Mexillón de Galicia/Mejillón de Galicia.

En 2016, la serie Turismo de ese año, compuesta por dos valores, volvía a mostrar entre sus motivos ilustrativos productos gastronómicos, en este caso, "la imagen con una copa representando el vino español (...) y la olla de barro que recuerda la gastronomía de interior" (Correos, 2016a: 14), haciendo referencia al turismo de playa y montaña respectivamente.

La elección de Toledo como Capital Española de la Gastronomía en el año 2016, llevó aparejada la emisión de un sello postal en la que se mostraba el mazapán como elemento alusivo al tema conmemorado; y la serie de ese año, compuesta por una hoja bloque de dos sellos correspondiente a las Denominaciones de Origen Protegidas, celebró dos productos de Castilla-La Mancha, como son el queso manchego y el azafrán de La Mancha (Fig. 6).

En 2017, y hasta conclusión de la redacción de este artículo, se emitieron varias series filatélicas con elementos relacionados directamente, no solo con el turismo, sino también con la gastronomía. Dejando aparte la serie Turismo de este año -dedicada al Año Internacional del turismo sostenible para el desarrollo-, que consta de dos sellos en los cuales solo se hace referencia al paisaje de playa en verano y de montaña en invierno, los sellos con referencias turístico-gastronómicas son varios.

El primero al que hacemos referencia es el que constituye la serie que conmemora la Capital Española de la Gastronomía, mención que este año ha recaído en la ciudad de Huelva (Fig. 7). En este sello, emitido en enero, pueden apreciarse productos típicos locales como sepias, gambas, fresones, jamón y vino blanco.

En septiembre se emite la serie compuesta por dos sellos en hoja bloque dedicada a las Denominaciones de Origen Protegidas que, en este caso, celebra dos productos típicos de la Región de Murcia: el arroz de Calasparra y el vino de Jumilla.

Por último, en cuanto a las emisiones filatélicas, hay que destacar la inauguración de "una nueva serie filatélica donde las provincias españolas serán las protagonistas de los sellos. 12 meses, 12 sellos, 12 provincias. Cada mes, una provincia española será la protagonista del sello que se venderá en dicha provincia" (Correos, 2017b: 14) y que "dará a conocer los elementos más emblemáticos, turísticos, reconocibles e identificativos de cada provincia" (Correos., 2017a: 7). Una estrategia que, obviamente, pretende favorecer el turismo, mostrando lo más destacado que se puede ofrecer al visitante: monumentos, paisajes, flora y fauna, tradiciones y, por supuesto, gastronomía. En el listado de los sellos de esta serie a emitidos hasta la fecha están las siguientes provincias, junto a las que destacamos entre paréntesis el o los elementos gastronómicos destacados en cada uno de los timbres: en enero, Guadalajara (miel de la Alcarria); en febrero, Cádiz (pescaíto frito y fino de Jerez); en marzo, Cáceres (pimentón de la Vera y el jamón ibérico); en abril, Barcelona (crema catalana) (Fig. 8); en mayo, Asturias (sidra y fabada) y Córdoba (salmorejo); en junio, Tarragona (Carquiñoles ${ }^{9}$ ); en julio, Las Palmas (plátano); en agosto, Santa Cruz de Tenerife (papas con mojo picón) y en septiembre, las Islas Baleares (ensaimada).

\section{Conclusión}

A lo largo de estas líneas hemos analizado el papel de los sellos de correos en tanto que instrumentos de promoción turística, a través de la gastronomía como motivo representado. La observación conjunta de las emisiones de sellos de correos, de la gestión turística y de sus políticas, así como de la evolución de la gastronomía y de sus nexos con el turismo, nos ha permitido observar interesantes pautas de comportamiento y evoluciones paralelas, cuando no claramente conectadas, que nos han llevado directamente sobre las líneas de desarrollo de la sociedad española misma a través de estos períodos.

Las representaciones propuestas a través de los sellos de correo han tenido un recorrido ideológico importante y aplicado a lo largo de todo el siglo XX, empleados como una herramienta promocional de, en un primer momento, monumentos y obras de interés artístico, así como de ciudades con potencial turístico; más adelante, durante la década de los años sesenta del pasado siglo, comenzó la promoción turística propiamente dicha a través de series específicas dedicadas a esta actividad y que fue comple- 
mentada por otras que conmemoraban edificios, folclore y obras de arte, así como otros aspectos del país que pudieran despertar el interés del posible turista, como son los paisajes y la flora y la fauna.

Y no será hasta finales de los años 80 cuando la gastronomía entre, de manera muy tímida, a ser considerada una actividad susceptible de ser incluida en el grupo de las posibles promotoras del turismo hacia España; algo más que evidente en los últimos años, en los que la presencia de la gastronomía y elementos relacionados directamente con ella es casi omnipresente tanto en los medios de comunicación en general como en la producción filatélica en particular.

Sin embargo, dicha relación de la gastronomía, hoy poco discutible, por un lado, con la cultura y con el patrimonio y, por otro, con el turismo, es relativamente reciente, y ha tenido que vencer una imagen de secundariedad propiciada tanto por el hecho de ser un aspecto cotidiano y, por lo tanto, poco valorado, como por la subalternidad propiciada por encontrarse, al menos en su parte más privada, ligada al ámbito de lo femenino.

Hoy en día, la imagen de prestigio de la gastronomía en relación con el global de la sociedad parece no ponerse en duda. Sin embargo, su evolución hasta el momento actual ha sido larga y, en ningún caso, fácil. Tal y como hemos podido observar a lo largo de este artículo, las imágenes gastronómicas (en nuestro caso, analizadas a través de la filatelia), algunos de los distintos momentos de la historia reciente del país y su correlación con las diferentes políticas institucionales llevadas a cabo, llevan a cabo un camino paralelo que, de cualquier modo, no es otro que el de la evolución de la propia sociedad española en su conjunto.

\section{Bibliografía}

Altman, Dennis

1991. Paper Ambassadors. The Politics of Stamps. Angus and Robertson, North Ryde.

Boletín Oficial del Estado

1944. "Orden de 5 de julio de 1944 por la que se fija el plan iconográfico en la elaboración de sellos de correos", Boletín Oficial del Estado, 191, 9 de julio, 5303-5304.

1959. "Orden de 10 de noviembre de 1959 sobre emission y puesta en circulación de los sellos de Correos correspondientes a la serie Monasterio de Guadalupe", Boletín Oficial del Estado, 273, 14 de noviembre, 14580.

1963. "Ley 197/1963, de 28 de diciembre, sobre 'Centros y Zonas de Interés Turístico Nacional”, Boletín Oficial del Estado, 313, 31 de diciembre, 18226-18230.

1964. "Orden de 26 de diciembre de 1963 sobre emission y puesta en circulación de los sello de la serie “Turismo", Boletín Oficial del Estado, 1, 1 de enero, 9.

Bonacina, Fabio

1998. Propaganda con i denti. Il francobollo come mezzo di comunicazione nelle relazioni internazionali, Vaccari, Vignola (Mo).

Brunn, Stanley D.

2001. "Stamps as iconography: Celebrating the independence of new European and Central Asian states", Geojournal, 52 (4): 315-323.

Bueno, Pilar y Ortega, Raimundo

1998. "De la fonda nueva a la nueva cocina. La evolución del gusto culinario en España durante los siglos

XIX y XX”, in Revista de Libros, 19-20: 1-20. http://www.revistadelibros.com/articulo_imprimible_pdf. php?art=3993\&t=articulos (accessed: Aug. 21rst, 2017).

Correos

2014a. "Filatelia al día", Sellos y mucho más 35 (1), 10-14.

2014b. "Filatelia al día", Sellos y mucho más 36 (2), 10-14.

2015a. "Fichas", Sellos y mucho más 39 (1), 13-20.

2015b. "Fichas", Sellos y mucho más 41 (3), 13-20.

2016a. "Fichas", Sellos y mucho más 43 (1), 13-22.

2016b. "Fichas", Sellos y mucho más 44 (2), 13-20.

2017a. "Nuevas emisiones", Sellos y mucho más 47 (1), 7.

2017b. "Fichas", Sellos y mucho más 47 (1), 13-22.

2017c. "Fichas", Sellos y mucho más 48 (2), 13-22.

2017d. "Correos presenta dos sellos dedicados al 'Año Internacional del Turismo Sostenible para el Desarrollo", Correos.es, 20 de febrero de 2017. [En línea]. [ref. de 12 de junio de 2017]. Accesible a través de la WWW: https://www.correos.es/ss/Satellite/site/info_corporativa-1363197033538-sala_prensa/ detalle_noticia-sidioma=es_ES 
Correyero, Beatriz

2011. "La propaganda turística y la política turística española durante el franquismo... cuando el turismo aún no era de masas" (Ponencia no publicada). Accesible en: http://www.ime.cat/WebEditor/Pagines/ file/Beatriz\%20Correyero.pdf

Dobson, Hugo

2002. "Japanese postage stamps: propaganda and decision making”, Japan Forum 14 (1): 21-39.

Duhart, Frédéric y Medina, F. Xavier

2009. "La paella en las culturas culinarias españolas y francesas (siglos XIX-XXI)". En Medina, F. Xavier, Ávila, Ricardo y De Garine, Igor (Coord.) Food, Imaginaries and Cultural Frontiers. Esays in Honour of Helen Macbeth. Guadalajara (México): Universidad de Guadalajara, Estudios del Hombre. Estefanía, Yolanda

2004. Octubre. "Los sellos que unen Europa", Abrecartas, 24: 30-31. (Octubre), 30-31.

Frewer, Douglas

2002. "Japanese postage stamps as social agents: some anthropological perspectives", Japan Forum 14 (1): 1-19.

Fribourg, Janine

1996. "Fêtes et cuisine traditionnelle en Espagne", en Bataille-Benguigui, Marie-Claire y Cousin,

Françoise (eds.) Cuisines, reflets des sociétés. París, Sépia-Musée de Homme.

Gell, Alfred

1998. Art and Agency: An Anthropological Theory. Oxford University Press.

González Turmo, Isabel

2007. "Patrimonio gastronómico, cultura y turismo. El caso de la España del siglo XX en el contexto mediterráneo". In Tresserras, Jordi and Medina, F. Xavier (eds.) Patrimonio gastronómico y turismo cultural en el Mediterráneo. Barcelona, Ibertur.

Hubert, Annie

2000. “Cuisine et politique: le plat national existe-t-il?", en Revue des Sciences Sociales, 27: 8-11.

Medina, F. Xavier

2005. Food Culture in Spain. Westport (CT), Greenwood Press.

Medina, F. Xavier

2017. "Reflexiones sobre el patrimonio y la alimentación desde las perspectivas cultural y turística". Anales de Antropología, 51(2): 106-113.

Navarro Oltra, Guillermo

2015a. "El sello postal del franquismo como autorretrato del Estado (pp. 12-19)". En Navarro Oltra, Guillermo (coord.). Autorretratos del Estado. El sello postal del franquismo. Segunda edición ampliada, Ediciones de la Universidad de Castilla-La Mancha / Publican Ediciones, Cuenca-Santander, pp. 12-19.

2015b. "Legitimación", en Navarro Oltra, Guillermo (coord.). Autorretratos del Estado. El sello postal de la Transición y la Democracia, Ediciones de la Universidad de Castilla-La Mancha / Publican Ediciones, Cuenca-Santander.

Pack, Sasha D.

2006. La invasión pacífica. Los turistas y la España de Franco. Madrid: Turner.

Pellejero, Carmelo

2004. "La política turística en España: una perspectiva histórica", in Las nuevas formas del turismo. Mediterráneo económico, 5. Almería, Cajamar. http://www.publicacionescajamar.es/pdf/publicaciones-periodicas/mediterraneo-economico/5/5-64.pdf (accessed: Aug. 22 ${ }^{\text {nd }}, 2017$ ).

Piera, Josep

2000. Els arrossos de casa $i$ altres meravelles. Barcelona: Empúries.

Serra Majem, Lluís and Medina, F. Xavier

2015. "The Mediterranean Diet as an Intangible and Sustainable Food Culture (pp. 37-46)". In Preedy,

Victor R. and Watson, Donald R. (eds.) The Mediterranean Diet: An Evidence-Based Approach.

London, Academic Press-Elsevier.

Scott, David

1995. European Stamp Design. A Semiotic Approach To Designing Messages. Academy Editions: Londres. Stoetzer, Carlos

1953. Postage Stamps as Propaganda. Washington: Public Affairs Press. 


\section{Strauss, Harlan J.}

1975. "Politics, Psychology and the Postage Stamp (pp. 157-180)". The Congress Book 1975: Forty-First American Philatelic Congress, The American Philatelic Congress, Federalsburg.

\section{Notas}

1 Referimos en este sentido, en relación con el turismo, a las interesantes obras de Pelejero (2004) o Pack (2006), que ofrecen anàlisis panorámicos de este período. En relación con la gastronomia, resulta interesante el recorrido que puede encontrarse en la obra de Bueno y Ortega (1998) o la de Medina (2005).

2 La guía del buen comer español. Inventario y loa de la cocina clásica de España y sus regiones, de Dionisio Pérez «Post-Thebussem", apareció en 1929 por encargo del Patronato Nacional del Turismo.

3 Desde entonces, cada año, se ha propuesto un tema, de manera que se transmita una idea de diversidad cultural, además de la afinidad a una idea de supranacionalidad. Y es que esta idea ha estado siempre presente desde que se constituyó la Unión Europea. La única excepción a esta norma fue en la emisión de 1984, año en que todos los países emitieron un motivo común de diseño similar para celebrar el vigésimo quinto aniversario de la CEPT. El motivo común elegido fue el del "Puente de la Cooperación Europea" (Estefanía, 2004:31).

4 Entre 2007 y 2013 se emitieron unas series de sellos dedicadas a la micología pero, aunque aparecen representados en ellas especímenes comestibles, también lo hacen ejemplares tóxicos y venenosos, por lo cual no hemos tomado aquí estas series en consideración.

5 Plato típico de Asturias, a base de alubias blancas (fabes, en asturiano).

6 Cocido típico castellano.

7 Sopa fría de color blanco, elaborada entre otros ingredientes con almendras y ajo.

8 La Dieta Mediterránea fue declarada como patrimonio Cultural Inmaterial de la Humanidad por la UNESCO en noviembre de 2010, tres una candidatura transnacional liderada desde España, y compuesta además por Italia, Grecia y Marruecos (Serra Majem y Medina, 2015).

$9 \quad$ Galletas secas, famosas por su dureza, elaborades con almendras tostadas (carquinyolis, en llengua catalana). 